\title{
NONISOTHERMAL NEWTONIAN FILM BLOWING
}

\author{
I. M.R. PINHEIRO \\ RMIT \\ Swanston St, Melbourne, Vic, Australia \\ E-mail: mrpprofessional@yahoo.com
}

\begin{abstract}
In this paper, we refine Han and Park results for nonisothermal film blowing: we propose a correction in their temperature and force balance equations, and prove that with this change the actual system should be split into three other systems, and use a different scaling supposedly more suitable to find the solution of the equations. Besides all that, we also provide an analysis on how our nonisothermal model could improve modeling of the film blowing process. It is worth mentioning that, even though we have corrected (mathematically) the force balance equation by Han and Park, we only make use of the first version of the split model in our simulations to match the other simulations done with the model so far. Future work will include further refinements on the simulations.
\end{abstract}

Key words: nonisothermal, film, blowing, newtonian, power-law

\section{Problem Formulation}

Temperature changes seem to influence how accurate the model describing the process of film blowing from die to die is. Having into sight what is mentioned in [5] we can see what major improvements are obtained by considering temperature changes that were disregarded by the isothermal models such as Tam's model [10]. There are a few temperature equations available in the present scientific community material such as Han and Park's, Alaie's, etc.

In [5], the model under analysis is for viscoelastic fluids, is described as being the 'Kelvin model' and it makes use of a reasonable different temperature equation when compared to ours. However, what is interesting for us there is the experimental data, which we do make use here.

We have made an analysis of Tam's results (see [10]) and found out that it is actually hard to get his equations working without using a negative initial slope for the radius curve, what makes the model inadequate. However, we may allow room for other possible values, not detected by us, being able to generate a faithful model. 
Tam's results also can be derived from Han and Park's work, just like ours. However, because our equations are easier to manipulate, include the temperature term, and give faithful bubble profiles for positive initial slopes of the radius curve, we have decided not to use Tam's equations and, rather, use ours.

The intention is obviously to reach a stage when mathematical results might become interesting for the industry in a way that it is worthwhile investing on them. If we can reach a close to $100 \%$ description of the actual results in the process, our results might turn out to be of interest for the industry which, nowadays, think that the waste of the material in the process is negligible. The waste under analysis, in this case, is obviously the waste of polymer melt once bad bubble formation leads to failure of the process and waste of material ${ }^{1}$.

In this paper we present a comparison between the isothermal newtonian model and the nonisothermal newtonian model, so that we provide the reader with the option to choose the most adequate one for describing each of the variables of interest in the problem: radius, velocity, and temperature. Our conclusion is that the nonisothermal model is better for the radius profile but is worse for the velocity profile and, obviously, better for the temperature profile.

\section{State of the Art}

Han and Park [3] obtained some results on nonisothermal newtonian fluids as a restriction of power-law fluids. Tam [10] took a completely newtonian approach, his results are dealing with the isothermal situation. Alaie and $\mathrm{Pa}-$ panastasiou [1] considered the nonisothermal situation of film blowing and treated it with an integral constitutive model. Kanai and White [4] produced an experimental study on the stability of nonisothermal (temperature dependent viscosity) film blowing of viscoelastic newtonian melts. Yamane and White [11] researched on the significance of non-newtonian viscosity on non-isothermal film blowing. From the empirical observation, one can get dynamic viscosity written as a function of temperature and frequency, wall shear stresses, pressure losses, wall-slip coefficients, shear and temperature dependent viscosities [11].

We now present these results from a different point of view: we use a different scaling, which is supposed to facilitate calculations, and prove that the system of equations expressing the process of nonisothermal newtonian film blowing should be split into three other systems. As a side result, we present an alternative to the force balance equation obtained by Han and Park. In this work, we depart from a generic situation of film blowing, providing all generic tensors and parameters, and work with power-law film blowing

\footnotetext{
${ }^{1}$ We have made some inquiries to plastic manufacturers who all gave us this information
} 
Table 1. Historical review of main results

\begin{tabular}{lll}
\hline Author/s & Model description & Limitations \\
\hline Pearson and Petrie [6,8] & Isothermal Newtonian & $\begin{array}{l}\text { Did not incorporate the } \\
\text { non-Newtonian flow behavior } \\
\text { of polymer melts }\end{array}$ \\
Han and Park [2] & Non-isothermal newtonian & $\begin{array}{l}\text { Did not account for } \\
\text { viscoelasticity }\end{array}$ \\
Kanai and White [4] & $\begin{array}{l}\text { Non-isothermal Newtonian with crystal- } \\
\text { lization }\end{array}$ & $\begin{array}{l}\text { Did not allow for non-Newtonian } \\
\text { behavior of fluid }\end{array}$ \\
Sidropoulos et al. [5] & Modified non-isothermal Newtonian & $\begin{array}{l}\text { Did not allow for viscoelastic } \\
\text { nature of polymer melt }\end{array}$ \\
Petrie [5] & $\begin{array}{l}\text { Non-isothermal Newtonian and } \\
\text { isothermal purely elastic model }\end{array}$ & $\begin{array}{l}\text { Did not allow for the viscoelastic } \\
\text { response of materials }\end{array}$ \\
\hline
\end{tabular}

(manufacture of plastic from fluids that obey the power-law rule), which then gets refined into newtonian film blowing. In short, this study provides a model for nonisothermal newtonian film blowing.

For the next table, we base ourselves on [5], just changing one line of [5]'s table, the line regarding Han and Park's work. That is because we consider their newtonian proposal, included in the power-law proposal instead of the power-law one. We strongly advise the reader to consult the sources mentioned in [5], which we paste here with some minor corrections, for righter history regarding research in the field. Therefore, the present state of the art is:

\section{Mathematical Models}

\subsection{Details about our model}

\subsubsection{Geometrical setup}

The basic problem we work with regards the process of manufacturing plastic. Below, in Figure 1 we present a sketch of the geometrical situation.

The process gets started with molten polymer at the beginning of the apparatus, at the die, where it reads $R_{0}$, the measure of the initial radius, and finishes with plastic film at the nip rolls up above. However, the region that interests us is the region between the annular die and the freeze line, where the polymer is cold enough to look like plastic film. That happens at $Z_{1}$, the freeze line. Further details on the picture of the region of interest may be found at [9].

\subsubsection{Strain tensors}

Because we are in a situation of tri-axial displacement, our strain matrix will look like the matrix below: 


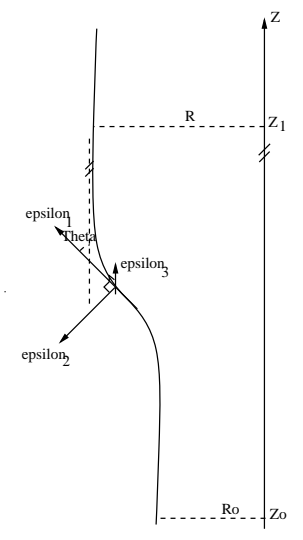

Figure 1. Half of the vertical cut in the bubble profile.

$$
e=\left\{\begin{array}{lll}
e_{1} & 0 & 0 \\
0 & e_{2} & 0 \\
0 & 0 & e_{3}
\end{array}\right\}
$$

The above matrix is a general agreement (see $[3,7,10]$, just to mention a few). It is adequate to comment that our film seems to keep on moving upwards. Therefore the logarithmic growth of velocity $e_{1}$, where $e_{1}=\ln \frac{U}{U_{0}}$, which can also be seen as a distance measure from initial to present velocity, must be greater than the logarithmic growth of thickness $e_{2}$, where $e_{2}=\ln \frac{E}{E_{0}}$, which can also be seen as a distance measure from initial to present thickness, and logarithmic growth of radius $e_{3}$, where $e_{3}=\ln \frac{R}{R_{0}}$, which can also be seen as a distance measure from initial to present radius.

Our film does not suffer from lateral displacement, i.e. $e_{2}=e_{3}$. Disagreement occurs, though, when it comes to the actual definition of strain tensors. We found it difficult to accept strain definitions other than the one proposed by Han and Park [2]. With $E_{0}$ being the initial thickness of the bubble, $U_{0}$ being the initial velocity, and $R_{0}$ being what was specified before, Han and Park propose that:

$$
e_{1}=\ln \left(\frac{R}{R_{0}}\right), e_{2}=\ln \left(\frac{E}{E_{0}}\right), e_{3}=\ln \left(\frac{U}{U_{0}}\right)
$$

along with

$$
e_{11}=\frac{1}{U} \frac{d U}{d T}, \quad e_{22}=\frac{1}{E} \frac{d E}{d T}, \quad e_{33}=\frac{1}{R} \frac{d R}{d T} .
$$

It seems reasonable to accept the above expressions as changes in the radius $R(Z)$, thickness $E(Z)$, and (meridional) velocity $U(Z)$ of the fluid, respectively, taking into consideration the definitions we exposed before and the fact that, after scaling is done 


$$
r_{0}=1, \quad w_{0}=1, \quad u_{0}=1 .
$$

Now, because the velocity vector goes tangentially to the bubble surface and forms an angle of $\theta$ degrees with the $Z$ axis, one has that $U \cos \theta=\frac{d Z}{d T}$ and, with this,

$$
\left\{\begin{array}{l}
e_{11}=\frac{1}{U} \frac{d U}{d T}=\cos \theta \frac{d U}{d Z} \\
e_{22}=\frac{1}{E} \frac{d E}{d T}=U \cos \theta \frac{1}{E} \frac{d E}{d Z} \\
e_{33}=\frac{1}{R} \frac{d R}{d T}=U \cos \theta \frac{1}{R} \frac{d R}{d Z}
\end{array}\right.
$$

\subsubsection{Continuity equation}

Because we are given an incompressible fluid, our continuity equation is

$$
e_{11}+e_{22}+e_{33}=0
$$

what implies that $e_{11}=-e_{22}-e_{33}$, that is,

$$
e_{11}=-U \cos \theta \frac{1}{E} \frac{d E}{d Z}-U \cos \theta \frac{1}{R} \frac{d R}{d Z}=-U \cos \theta\left(\frac{1}{E} \frac{d E}{d Z}+\frac{1}{R} \frac{d R}{d Z}\right),
$$

as mentioned in [2]. In a continuous steady state operation of an incompressible fluid, though, the total volumetric flow rate through the die is kept constant, that is:

$$
Q=2 \pi R E U=\text { const, }
$$

where $U$ is the meridional velocity component in the $\epsilon_{1}$ direction, $R$ is the local bubble radius, and $E$ is the local film thickness [5].

But our problem is axisymmetric and, therefore, the velocity in the transverse direction is zero, while the velocity in the normal direction is negligible [5], what leaves us solely with the meridional velocity, that is, $U$ is equal to meridional velocity. Now, we can infer that:

$$
\begin{aligned}
& e_{11}=-\frac{Q}{2 \pi R E} \cos \theta\left(\frac{1}{R} \frac{d R}{d Z}+\frac{1}{E} \frac{d E}{d Z}\right), \\
& e_{22}=\frac{Q}{2 \pi R E} \cos \theta \frac{1}{E} \frac{d E}{d Z}, \\
& e_{33}=\frac{Q}{2 \pi R E} \cos \theta \frac{1}{R} \frac{d R}{d Z} .
\end{aligned}
$$

that bring us to the following rate-of-strain matrix: 


$$
e=\frac{Q \cos \theta}{2 \pi R E}\left\{\begin{array}{ccc}
-\left(\frac{1}{R} \frac{d R}{d Z}+\frac{1}{E} \frac{d E}{d Z}\right) & 0 & 0 \\
0 & \frac{1}{E} \frac{d E}{d Z} & 0 \\
0 & 0 & \frac{1}{R} \frac{d R}{d Z}
\end{array}\right\}
$$

which is mentioned in [2].

\subsubsection{Stress tensor}

In our system, it is present the 'plane' or biaxial stress. This means that the stress over the second axis is null (shear stress), what matches Han and Park's dispositions about it. Besides this, according to the newtonian laws, stress and strain relate in the following form:

$$
T_{i j}=-p \delta_{i j}+t_{i j}
$$

where $p$ represents the isotropic pressure, $T$ represents stress, $t$ represents strain. In an isothermal situation, one can say that [2]

$$
\eta_{b}=2 \eta_{0}
$$

In the isothermal newtonian case, therefore, $t_{i j}=2 \eta_{0} e_{i j}$ and, as a generalization, the power-law case gives $t_{i j}=\eta_{b} e_{i j}$. With all the above, one can say that, in the nonisothermal newtonian film blowing, the stress matrix looks like:

$$
T=\left\{\begin{array}{ccc}
\eta_{b}\left(e_{11}-e_{22}\right) & 0 & 0 \\
0 & 0 & 0 \\
0 & 0-\eta_{b}\left(2 e_{22}+e_{11}\right)
\end{array}\right\}
$$

\subsubsection{Force balance equation in meridional direction}

Both in the elongational and in the stretching situations, one can make use of the force equation from [2]. This is because the force that acts on an element of fluid is the same independently from the situation being considered. In [2], the authors take into account the elongational viscosity, which is also considered in newtonian film blowing, the only difference being that, in film blowing, the rate between elongational viscosity and initial viscosity must be a constant. Then the equation is given by

$$
F(Z)=F_{0}+\pi \Delta p\left(R^{2}-R_{0}^{2}\right)+2 \pi \rho g \int_{0}^{Z} R E \frac{d Z}{\cos \theta}
$$

but, it is also known that

$$
F(Z)=T_{11} d A 1 \cos \theta=2 \pi R E T_{11} \cos \theta,
$$

where $d A 1$ is an infinitesimal part of the fluid element under consideration. 


\subsubsection{Equation 1: total composition of forces}

Here, we propose a small correction of the formula presented by Han and Park in [2]. We agree with Han and Park up to the point they claim that

$$
\Delta P=\frac{P_{L}}{R_{1}}+\frac{P_{H}}{R_{3}}-\rho g E \sin \theta
$$

agreeing with Bernoulli's equation for incompressible fluids. One can easily see three forces acting on the wall of the bubble: one that provokes displacement in the vertical direction $F_{1}$, which makes the fluid go upwards and provokes lateral displacement; $F_{3}$, which makes the bubble inflate, and one coming from the weight of the fluid, $F_{2}$, which is going to be the only negative force present in the system.

Therefore, one may say that:

$$
F_{R}=\Delta p D E_{h} D E_{l}=F_{1}+F_{3}-F_{2},
$$

where one has, respectively, the centrifugal force, $F_{1}$, the normal component of gravity, $F_{2}=\rho g E \sin \theta$ and the surface tension forces, $F_{3}$.

We now put each of the vectors in the normal direction. Once $F_{\Delta_{p}}$ is already in the normal direction, we only rotate the other three forces. We call $\alpha_{1}$ the angle between the force and the $\epsilon_{1}$ axis, and we call $\alpha_{2}$ the angle between the force and the $\epsilon_{2}$ axis, see Fig 2. Therefore,

$$
\begin{aligned}
& F_{1}=T_{11} * \text { Area } * \text { rotation }=2 T_{11} d E_{h} E \sin \alpha_{1}, \\
& F_{2}=\rho g E \sin \theta, \\
& F_{3}=T_{33} * \text { Area } * \text { rotation }=2 T_{33} d E_{l} E \sin \alpha_{2} .
\end{aligned}
$$

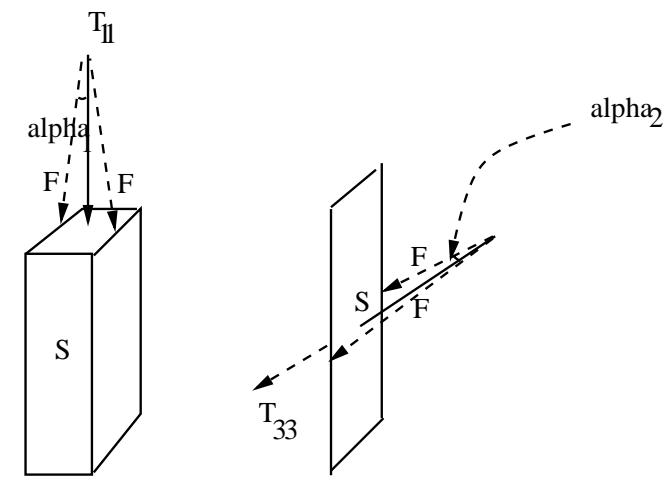

Figure 2. Forces on the wall of the bubble.

An accurate approximation to the sines of the angles involved is given bellow: 


$$
\sin \alpha_{1} \approx \alpha_{1} \approx \frac{d E_{l}}{2 R_{1}}, \quad \sin \alpha_{2} \approx \alpha_{2} \approx \frac{d E_{h}}{2 R_{3}},
$$

where $R_{1}$ and $R_{3}$ are the modulus of the forces whose sum is equivalent to the stress itself once their resultant passes through the center of pressure ${ }^{2}$.

With this approximation one ends up obtaining the following equation:

$$
\Delta P=\frac{T_{11} E}{R_{1}}+\frac{T_{33} E}{R_{3}}-\rho g E, \sin \theta
$$

and usuing $T_{11} E, P_{L}, T_{33} E, P_{H}$, one gets

$$
\Delta P=\frac{P_{L}}{R_{1}}+\frac{P_{H}}{R_{3}}-\rho g E \sin \theta .
$$

$R_{1}$ may be approximated by the radius of curvature of the bubble, which may be expressed as:

$$
R_{1}=\frac{\left|R^{\prime \prime}\right|}{\left[1+\left(R^{\prime}\right)^{2}\right]^{\frac{3}{2}}}
$$

where' denotes a derivative towards the $Z$ axis. It is well known that

$$
\left[1+\left(R^{\prime}\right)^{2}\right]^{\frac{3}{2}}=\frac{1}{\cos ^{3} \theta} .
$$

Therefore,

$$
R_{1}=\frac{1}{\frac{\left|R^{\prime \prime}\right|}{(\cos \theta)^{-3}}} .
$$

On the other hand, $R_{3}$ runs parallel to the surface and in right angle with the radius. Therefore, it forms $\theta$ degrees with the radius and may be expressed as

$$
R_{3}=\frac{R}{\cos \theta} .
$$

With all these equalities, our total force balance might be expressed as

$$
\Delta P=\frac{P_{L}}{R_{L}}+\frac{P_{H}}{R_{H}}-\rho g E \sin \theta,
$$

where

$$
P_{L}=T_{11} E, \quad P_{H}=T_{33} E, \quad R_{L}=\frac{1}{\frac{\left|R^{\prime \prime}\right|}{(\cos \theta)^{-3}}}, \quad R_{H}=\frac{R}{\cos \theta}
$$

We now use the definitions for $T_{11}$ and $T_{33}$ given above:

$$
T_{11}=\eta_{b}\left(e_{11}-e_{22}\right), \quad T_{33}=-\eta_{b}\left(2 e_{22}+e_{11}\right),
$$

that is:

\footnotetext{
${ }^{2}$ Dr. Richard Kelso, Adelaide University, personal communications
} 


$$
\begin{aligned}
& T_{11}=\eta_{b}\left(\left[-\frac{Q \cos \theta}{2 \pi R E}\left(\frac{1}{R} \frac{d R}{d Z}+\frac{1}{E} \frac{d E}{d Z}\right)\right]-\left[\frac{Q \cos \theta}{2 \pi R E} \frac{1}{E} \frac{d E}{d Z}\right]\right), \\
& T_{33}=-\eta_{b}\left(2\left[\frac{Q \cos \theta}{2 \pi R E} \frac{1}{E} \frac{d E}{d Z}\right]-\left[\frac{Q \cos \theta}{2 \pi R E}\left(\frac{1}{R} \frac{d R}{d Z}-\frac{1}{E} \frac{d E}{d Z}\right)\right]\right) .
\end{aligned}
$$

By using the adequate scaling, explained further below in this section, in order to get more initial values, and using our material function explained in the next section, we get:

$$
\begin{array}{r}
2 B r^{3} u\left(1+\left(C r^{\prime}\right)^{2}\right)^{2}-C\left(1+\left(C r^{\prime}\right)^{2}\right)\left(2 r^{\prime} u+r u^{\prime}\right)+r C^{3}\left(r^{\prime} u+2 r u^{\prime}\right)\left|r^{\prime \prime}\right| \\
+A C r^{2} r^{\prime}\left(1+\left(C r^{\prime}\right)^{2}\right)^{\frac{3}{2}}=0
\end{array}
$$

Our scaling, so far, is $r=\frac{R}{R_{0}}, u=\frac{U}{U_{0}}$ and the constants involved are:

$$
A=\frac{\rho g R_{0}^{2}}{\eta_{0} U_{0}}, \quad B=\frac{\pi \Delta p R_{0}^{3}}{\eta_{0} Q}, \quad C=\frac{R_{0}}{Z_{1}} .
$$

\subsubsection{Material Function}

According to Han and Park [3], one verifies the following viscosity relationship for a nonisothermal newtonian film blowing:

$$
\eta_{b}=\eta_{0} \exp \left(\frac{(1 / s(z)-1) E}{R T_{0}}\right)=\eta_{0} \exp \left(\beta\left(\frac{1}{s(z)}-1\right)\right)
$$

where we use notation $\beta=\frac{E}{R T_{0}}$.

\subsubsection{Equation 3: temperature equation}

We use Han and Park's temperature equation provided in [3]:

$$
s^{\prime}=-D r \sec \theta\left(s-s_{a}\right)+Y r \sec \theta\left(s^{4}-s_{a}^{4}\right),
$$

where

$$
D=\frac{U R_{0} 2 \pi Z_{1}}{Q \rho C_{v}}, \quad Y=T_{0}^{3} \frac{R_{0} 2 \pi Z_{1} \lambda \epsilon}{Q \rho C_{v}}, \quad s_{a}=\frac{T_{a}}{T_{0}},
$$

$T_{a}$ is the environmental air temperature, $T=T(Z)$ is temperature of the bubble, which varies with height and $s(z)=\frac{T(z)}{T_{0}}$.

We made a small correction in the sign, which might easily have been a 'typo' in their work because of the fact that the temperature should go down in the process and not up. 


\subsubsection{Scaling}

We make use of a scaling for $r, s$ and $u$ that differs from the one chosen by Han and Park because ours will provide us with simpler initial conditions:

$$
r(0)=1, \quad s(0)=1, \quad u(0)=1, \quad w(0)=1 .
$$

Han and Park choose to scale all variables against $a_{0}$, the radius at the annular die. We scale $z$ against $Z_{1}$, the freeze line height. With this, $z=1$ at the freeze line height. Our process, therefore, takes place between $z=0$ and $z=1$, a standard interval. We then propose:

$$
\eta=\frac{\eta_{b}}{\eta_{0}}, \quad z=\frac{Z}{Z_{1}}, \quad r=\frac{R}{R_{0}}, \quad u=\frac{U}{U_{0}}, \quad s=\frac{T}{T_{0}}, \quad w=\frac{E}{E_{0}} .
$$

\subsubsection{Resulting System}

As a result from the previous function and equations (3.1), (3.2), (3.4), (3.5), one gets to describe thermal effects on a newtonian film blowing situation through the following system:

$$
\left\{\begin{aligned}
2 B r^{3} u\left(1+\left(C r^{\prime 2}\right)^{2}\right)+A C r^{2} r^{\prime}(1+ & \left.\left(C r^{\prime}\right)^{2}\right)^{\frac{3}{2}}+C^{3}\left|r^{\prime \prime}\right|\left(2 r^{2} u^{\prime}+u r r^{\prime}\right) \eta \\
& -C\left(1+\left(C r^{\prime}\right)^{2}\right)\left(2 u r^{\prime}+r u^{\prime}\right) \eta=0 \\
C\left(1+C^{2}\left(r^{\prime}\right)^{2}\right)^{-1}\left(\frac{r^{\prime} u+2 u^{\prime} r}{u r}\right)= & f_{0}\left(\eta^{-1}\right)+B\left(r^{2}-1\right)\left(\eta^{-1}\right) \\
& +\frac{A}{C} \eta^{-1} \int_{0}^{Z} \frac{1}{u}\left(1+C^{2}\left(r^{\prime}\right)^{2}\right)^{-\frac{1}{2}} d z \\
s^{\prime}=-\operatorname{Dr}\left(\left(1+C^{2}\left(r^{\prime}\right)^{2}\right)^{\frac{1}{2}}\right)\left(s-s_{a}\right)- & Y r\left(\left(1+C^{2}\left(r^{\prime}\right)^{2}\right)^{\frac{1}{2}}\right)\left(s^{4}-s_{a}^{4}\right) .
\end{aligned}\right.
$$

\subsubsection{Getting ready to solve the system}

To correctly analyze our problem from a mathematical point of view, we need to rewrite the first equation of the system, making three systems out of one system given above, since $r^{\prime \prime} \geq 0$ for $z \in[0, a)$ and $r^{\prime \prime} \leq 0$ for $z \in(a, 1]$, what gives us $r^{\prime \prime}=0$ at our inflexion point. Therefore, for $z \in[0, a)$, we have the equation

$$
\begin{aligned}
2 B r^{3} u\left(1+\left(C r^{\prime 2}\right)^{2}\right)+A C r^{2} r^{\prime}(1 & \left.+\left(C r^{\prime}\right)^{2}\right)^{\frac{3}{2}}+C^{3} r^{\prime \prime}\left(2 r^{2} u^{\prime}+u r r^{\prime}\right) \eta \\
& -C\left(1+\left(C r^{\prime}\right)^{2}\right)\left(2 u r^{\prime}+r u^{\prime}\right) \eta=0
\end{aligned}
$$

while for $z \in(a, 1]$ :

$$
\begin{aligned}
2 B r^{3} u\left(1+\left(C r^{\prime 2}\right)^{2}\right)+A C r^{2} r^{\prime}(1 & \left.+\left(C r^{\prime}\right)^{2}\right)^{\frac{3}{2}}-C^{3} r^{\prime \prime}\left(2 r^{2} u^{\prime}+u r r^{\prime}\right) \eta \\
& -C\left(1+\left(C r^{\prime}\right)^{2}\right)\left(2 u r^{\prime}+r u^{\prime}\right) \eta=0
\end{aligned}
$$


and, finally, when $z=a$, we have our inflexion point and $r^{\prime \prime}=0$ :

$$
\begin{aligned}
2 B r^{3} u\left(1+\left(C r^{\prime 2}\right)^{2}\right)+ & A C r^{2} r^{\prime}\left(1+\left(C r^{\prime}\right)^{2}\right)^{\frac{3}{2}} \\
& -C\left(1+\left(C r^{\prime}\right)^{2}\right)\left(2 u r^{\prime}+r u^{\prime}\right) \eta=0
\end{aligned}
$$

all with the same parameters, material function, and scaling. The initial conditions are given by (3.6).

\section{Analysis of the Accuracy of the Models Involved: Isothermal and Nonisothermal Models by Han and Park}

Here, we compare the results obtained by means of our model (Han and Park with corrections) against the results of the isothermal newtonian model described in the same way but for the $\eta$ term, which becomes $2 \eta_{0}$ in the isothermal newtonian case. We also measure both against the experimental results mentioned in the works of Battacharya et al. [5]. In what follows, we present the graphics for temperature, radius, and velocity variations during the process of film blowing under modeling, which actually refers to the heights between zero and one on the $Z$ axis. The results are presented in Figure 3

- About the graphic on temperature variations in newtonian film blowing: One can clearly notice on the graphic above that the nonisothermal version of the model proposed by Han and Park is closer to the description of the experimental data than the isothermal version, however both are inaccurate.

- About the graphic on radius variations in newtonian film blowing: nonisothermal version of the model proposed by Han and Park is a much more accurate description regarding the experimental data than the isothermal one. One must also be reminded that the last point of the experimental data does not exist and was placed there for clarity of exposition due to Maple constraints.

- About the graphic on velocity variations in newtonian film blowing: this is the only case where the isothermal model describes the experimental data more accurately than the nonisothermal one. The last point in the experimental data must be disregarded since it was placed there for the purposes of the Maple package display becoming better.

\section{Conclusions}

We presented a revised mathematical model for simulation of thermal effects on newtonian blown film process which is more accurate than the ones existing so far. It takes into account heat transfer between the molten film and the coolant, and the effect of gravity. This model is, ultimately, a refinement of the model by Han and Park. We conclude that the nonisothermal model improves the isothermal model in terms of the radius profile but presents worse results 


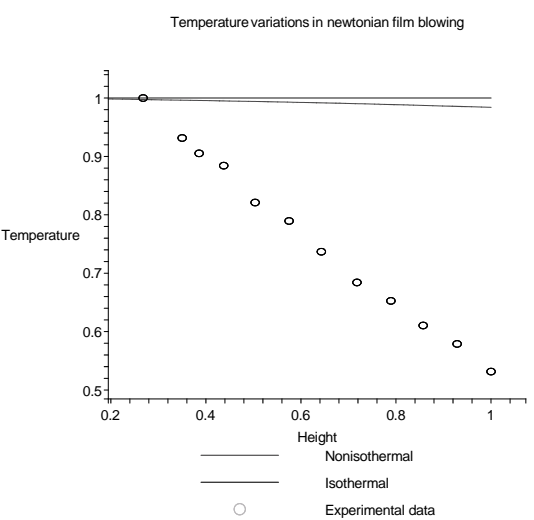

a)

Velocity in newtonian film blowing ( $\mathrm{mm} X \mathrm{~mm} / \mathrm{s})$

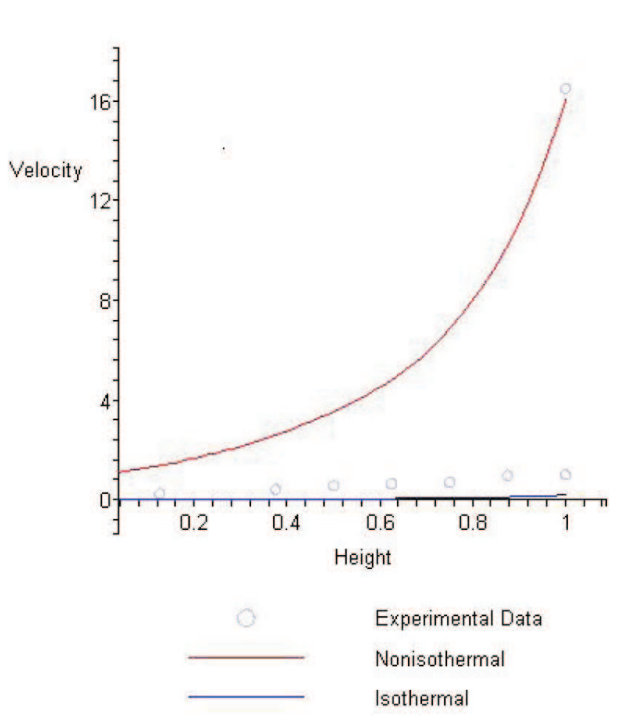

c)

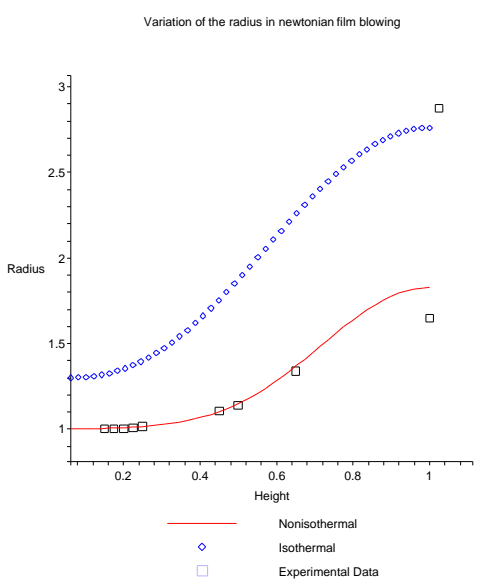

b)

Figure 3. Newtonian film blowing: a) temperature variations, b) variation of the radius, c) velocity.

when it comes to velocity. And, trivially, it is a better model for temperature changes. In future work, we intend to study the connection between the two models and work towards a balanced model in terms of proximity with the experimental results. We also intend to perform simulations with the split system once, in this work, all we did was keeping the line of the works already done in the field which work only with the first presented version of the system. 
Also a novelty for this work was a scaling that differs from the ones used so far, which makes computations easier.

\section{Acknowledgements}

The author would like to thank Dr. John Shepherd, more specially; Dr. Bill Blyth, and Dr. John Gear, from RMIT, and Dr. Richard Kelso from Adelaide university for the useful hints and teachings on the subject of the paper. In what regards resources, the author would like to thank Dr. Chris Tysdell from UNSW. In what regards help with Maple, it is definitely worth to publicly thank the lecturer Dominic Tam from RMIT.

\section{References}

[1] S.M. Alaie and T.C. Papanastasiou. Modeling of non-isothermal film blowing with integral constitutive equations. Hanser Publishers, 1993.

[2] C.D. Han and J.Y. Park. Studies on Blown Film Extrusion I. Experimental determination of Elongational Viscosity. Journal of Applied Polymer Science, 19, $3257-3276,1975$.

[3] C.D. Han and J.Y. Park. Studies on Blown Film Extrusion II. Analysis of the Deformation and Heat Transfer Processes. Journal of Applied Polymer Science, 19, $3277-3290,1975$.

[4] T. Kanai and J.L. White. Dynamics and stability of the tubular film extrusion of various polyethylenes. Polym. Eng. Sci., 24, $1185-1201,1984$.

[5] S. Muke, H. Connell and S.N. Bhattacharya. Numerical modelling and experimental verification of blown film processing. Journal of Non-Newtonian Fluid Mechanics $A U, 2003$.

[6] J.R. Pearson and C.J.S. Petrie. The flow of a tubular film. part 2. interpretation of the model and discussion of solutions. J. Fluid Mech., 42(60), 1970.

[7] J.R.A. Pearson. Mechanics of Polymer Processing. Elsevier Applied Science, USA, 1985.

[8] J.R.A. Pearson and C.J.S. Petrie. The flow of a tubular film. part 1. formal mathematical representation. J.Fluid Mech., 40(1), 1970.

[9] J.J. Sheppherd, H.J. Connell and D.C.H. Tam. An Interior Layer in a FilmBlowing Problem. preprint, RMIT, 2005.

[10] D.C.H. Tam. Mathematical Analysis of the Blown Newtonian Film. RMIT, Department of Mathematics and Statistics, 2003.

[11] H. Yamane and J.L. White. Int. Polym. Process, 2, 107, 1987. 
Neizoterminis Niutoninio filmo juostos pūtimas

I.M.R. Pinheiro

Šiame straipsnyje tobulinami Hano ir Parko rezultatai apie neizotermini filmo juostos pūtimą. Autoriai patikslina temperatūros ir jègų balanso lygtis ir įrodo, kad tai išskaido lygčiu sistemą i tris sistemas. Tai ịgalina rasti uždavinio sprendinị. Taip pat pateikta analizè kaip šis modelis, gali patobulinti pūtimo procesą. Kadangi naudojamas pataisytas Hano ir Parko modelis, todèl modeliuojant gauti rezultatai ne visuomet sutampa su kitų eksperimentų rezultatais. Ateityje numatoma tobulinti šiuos eksperimentus. 